\title{
Successful umbilical cord blood stem cell transplantation in a child with WHIM syndrome
}

Gergely Kriván ${ }^{1}$, Melinda Erdős ${ }^{2}$, Krisztián Kállay ${ }^{1}$, Gábor Benyó ${ }^{1}$, Ágnes

Tóth $^{1}$, János Sinkó ${ }^{1}$, Vera Goda ${ }^{1}$, Beáta Tóth ${ }^{2}$, László Maródi ${ }^{2}$

${ }^{1}$ Department of Pediatric Hematology and Stem Cell Transplantation, United Szent István and Szent László Hospital, Budapest; ${ }^{2}$ Department of Infectious and Pediatric Immunology, Medical and Health Science Center, University of Debrecen, Debrecen, Hungary

Correspondence László Maródi, MD, PhD, Department of Infectious and Pediatric Immunology, Medical and Health Science Center, University of Debrecen, Nagyerdei Krt. 98, H-4032 Debrecen, Hungary. Tel: +36 52255 416; Fax: +36 52430 323; e-mail:

Imarodi@dote.hu 


\section{To the Editor:}

WHIM (warts-hypogammaglobulinemia-infections-myelokathexis) syndrome is an autosomal dominant primary immunodeficiency disorder caused by mutation of the CXC chemokine receptor 4 (CXCR4) gene $(1,2)$. Affected patients suffer from recurrent infections of the respiratory tract and soft tissues, and marked susceptibility to warts caused by human papilloma viruses from the second decade of life $(3,4)$. Granulocyte-macrophage colony stimulating factor (G-CSF) has been used to increase and maintain an adequate number of circulating neutrophils, and administration of intravenous immunoglobulin (IVIG) concentrates may help to decrease the number of infectious episodes caused by extracellular pathogens $(5,6)$. Nevertheless, the optimal therapy of patients with WHIM has not been clearly defined and patients continue to develop infections despite combination therapy with G-CSF and IVIG. None of the patients reported before has received hematopoietic stem cell transplantation (HSCT). We describe here a successful allogeneic HSCT in a girl with WHIM syndrome caused by c.1013G $>$ C sequence variant in the CXCR4 gene.

Clinical and genetic details of this girl were described in the Journal before (2). IVIG infusions and varying doses of G-CSF were started at 6 and half years of age (2). She showed clinical improvement in the beginning but continued to develop respiratory infections leading to chronic obstructive pulmonary disease afterwards. At age 8 she was treated for a prolonged episode of dental periostitis complicated with purulent lymphadenitis. We counseled the family on the possibility of HSCT and umbilical cord blood (UCB) transplantation and the mother decided to become pregnant. She presented with a new pregnancy and at 11 weeks of gestation prenatal genetic testing revealed wild type CXCR4 sequences and HLA genotyping showed matching between the patient and the fetus (Fig. 1). Informed consent was obtained from the parents and the UCB transplantation was approved by the Hungarian National Transplant Committee. Umbilical cord blood stem cells were collected by standard methods 
(7). Pretransplant conditioning regimen consisted of intravenous busulphan and cyclophosphamide, followed by a course of rabbit anti-thymocyte globulin. An UCB graft containing $1.2 \times 10^{5} \mathrm{CD} 34^{+}$cells $/ \mathrm{kg}$ and $3.8 \times 10^{7}$ nucleated cells $/ \mathrm{kg}$ was infused without any adverse effects. Graft versus host disease (GvHD) prophylaxis consisted of methylprednisolone and cyclosporin A. A flare up of chronic obstructive bronchitis was observed, and on day +49 she developed pneumonia caused by Str. pneumoniae. Meropenem therapy and bronchodilatator drugs resolved this lung infection. No signs or symptoms of acute or chronic GvHD were observed. An absolute neutrophil count of $>500 / \mathrm{mm}^{3}$ was achieved on post-transplant day 32, and platelet transfusion independence was achieved on day 48 . Reconstitution of the humoral immune system was also robust with normal-for-age serum IgG, IgM, and IgA levels by 100 days after HSCT.

Interphase chromosome analysis and serial variable number of tetra- and pentanucleotid repeats examinations were used to confirm donor cell engraftment. The first chimerism studies at day +55 post-transplant revealed $12 \%$ persisting recipient cells, but subsequent serial chimeric analyses demonstrated almost full donor chimerism with less than 5\% recipient cells. During follow-up the patient's peripheral blood counts and serum immunoglobulin concentrations have normalized without any cytokine or IVIG support. One year after transplant the patient has near normal hematologic and immunologic parameters. She attends school and takes no medication, and is free of infections or post-transplant complications. Importantly, chronic lung disease was resolved and she is not taking bronchodilator agents.

In children with WHIM syndrome the diagnosis and supportive treatment with IVIG and/or G-CSF may be delayed and severe morbidity or premature death among young individuals have been reported. Fatal outcomes due to septicaemia and fulminant Epstein-Barr virus positive intestinal B cell lymphoma have been described (8). Furthermore warts are 
generally therapy-resistant requiring repeated laser ablation for management. In addition, the long-term use of supportive therapy can cause significant lifestyle restrictions and poor quality of life and entails significant costs for health care budget as well. Thus, there is a rationale for allogeneic hematopoietic stem cell transplantation as a curative treatment option in patients with WHIM syndrome. 


\section{References}

1. Hernandez PA, Gorlin RJ, Lukens JN, Taniuchi S, Bohinjec J, Francois F. et al. Mutations in the chemokine receptor gene CXCR4 are associated with WHIM syndrome, a combined immunodeficiency disease. Nat Genet 2003; 34:70-4.

2. Alapi K, Erdős M, Kovács G, Maródi L. Recurrent CXCR4 sequence variation in a girl with incomplete WHIM syndrome. Eur J Haematol 2007; 78:86-8.

3. Siedlar M, Rudzki Z, Strach M, Trzyna E, Pituch-Noworolska A, Błaut-Szlósarczyk A, et al. Familial occurrence of warts, hypogammaglobulinemia, infections, and myelokathexis (WHIM) syndrome. Arch Immunol Ther Exp 2008; 56:419-25.

4. Gorlin RJ, Gelb B, Diaz GA, Lofsness KG, Pittelkow MR, Fenyk JR, Jr. WHIM syndrome, an autosomal dominant disorder: clinical, hematological, and molecular studies. Am J Med Genet 2000; 91:368-76.

5. Aprikyan AA, Liles WC. Park JR, Jonas M, Chi EY, Dale DC. Myelokathexis, a congenital disorder of severe neutropenia characterized by accelerated apoptosis and defective expression of bcl-x in neutrophil precursors. Blood 2000; 95:320-7.

6. Hord JD, Whitlock JA, Gay JC, Lukens JN: Clinical features of myelokathexis and treatment with hematopoietic cytokines: a case report of two patients and review of the literature. J Pediatr Hematol Oncol 1997; 19:443-8.

7. Miano M, Labopin M, Hartmann O, Angelucci E, Cornish J, Gluckman E, et al. Haematopoietic stem cell transplantation trends in children over the last three decades: a survey by the paediatric diseases working party of the European Group for Blood and Marrow Transplantation. Bone Marrow Transplant 2007; 39:89-99.

8. Imashuku S, Miyagawa A, Chiyonobu T, Ishida H, Yoshihara T, Teramura T, et al. Epstein-Barr virus-associated T-lymphoproliferative disease with hemophagocytic 
syndrome, followed by fatal intestinal B lymphoma in a young adult female with WHIM syndrome. Ann Hematol 2002; 81:470-3. 
Figure 1. (A) Clinical phenotype of the patient with WHIM syndrome and her relatives. Half-filled circle, the female patient with WHIM; interrupted square, male fetus. (B) Automated sequencing profile of genomic DNA showing heterozygous c.1013C $>$ G mutation in exon 2 of the $C X C R 4$ gene int he patient and wild type sequences in her parents and the male fetus. Mutation position is encircled. In hemizygous patients the $c .1013 \mathrm{C}>\mathrm{G}$ sequence variant is predicted to result in p.S338X truncation mutation of the chemokine receptor CXCR4. m, mutant; wt. wild type. 
Figure 1

A

I.

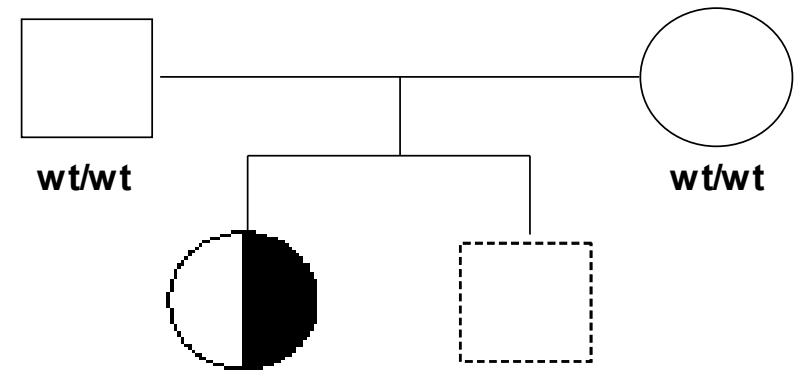

B

m/wt wt/wt

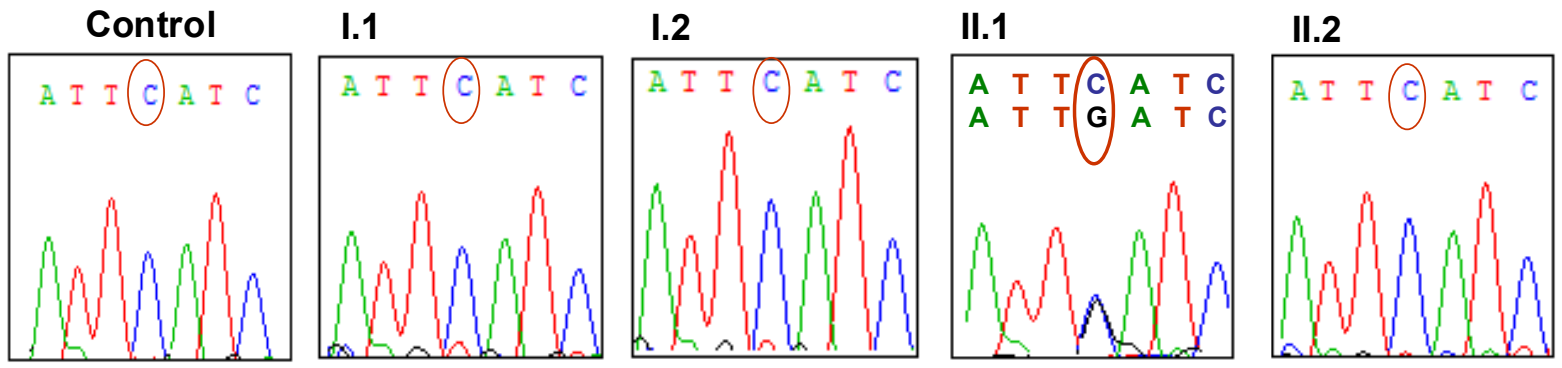

